\title{
Immunosuppressive Factor MNSF $\beta$ Regulates Cytokine Secretion by Mouse Lymphocytes and Is Involved in Interactions between the Mouse Embryo and Endometrial Cells In Vitro
}

\author{
Yaping He, ${ }^{1,2}$ Zhaogui Sun, ${ }^{2}$ Yan Shi, ${ }^{2}$ Yahong Jiang, ${ }^{2}$ Zhefu Jia, ${ }^{2}$ Yanbo Du, ${ }^{2}$ \\ Lois A. Salamonsen, ${ }^{3}{\text { Zhuoya } \mathrm{Li}^{1}{ }^{1} \text { and Jian Wang }}^{2}$ \\ ${ }^{1}$ Department of Immunology, School of Basic Medical Sciences, Tongji Medical College, Huazhong University of Science and Technology, \\ Wuhan 430030, China \\ ${ }^{2}$ NPFPC Key Laboratory of Contraceptive Drugs and Devices, Shanghai Institute of Planned Parenthood Research, Shanghai 200032, \\ China \\ ${ }^{3}$ Prince Henry's Institute of Medical Research, Clayton, VIC 3168, Australia
}

Correspondence should be addressed to Zhuoya Li, zhuoyalitj@163.com and Jian Wang, wangjiansippr@126.com

Received 5 August 2011; Accepted 5 September 2011

Academic Editors: E. K. Kapsogeorgou and V. Patella

Copyright (๑) 2011 Yaping He et al. This is an open access article distributed under the Creative Commons Attribution License, which permits unrestricted use, distribution, and reproduction in any medium, provided the original work is properly cited.

Immune tolerance at the fetomaternal interface must be established during the processes of implantation and pregnancy. Monoclonal nonspecific suppressor factor beta (MNSF $\beta$ ) is a secreted protein that possesses antigen-nonspecific immunesuppressive function. It was previously reported that intrauterine immunoneutralization of MNSF $\beta$ significantly inhibited embryo implantation in mice. In the present study, MNSF $\beta$ protein expression was up- or downregulated by overexpression or RNA interference, respectively, in HCC-94 cells and the culture supernatants used to determine effects of MNSF $\beta$ on the secretion of IL-4 and TNF $\alpha$ from mouse lymphocytes as detected by ELISA. A coculture model of mouse embryos and endometrial stromal cells was also utilized to determine the effects of a specific anti-MNSF $\beta$ antibody on hatching and growth of embryos in vitro. The results show that MNSF $\beta$ induced secretion of IL- 4 and inhibited secretion of TNF $\alpha$ from mouse lymphocytes. Following immunoneutralization of MNSF $\beta$ protein in the HCC-94 supernatant, the stimulatory effect of MNSF $\beta$ on IL- 4 secretion from mouse lymphocytes was reduced, while the inhibitory effect on secretion of TNF $\alpha$ was abrogated. Expression of MNSF $\beta$ was detected in both embryonic and endometrial stromal cells, and its immunoneutralization inhibited the hatching and spreading of embryos in an in vitro coculture model. These results indicated that MNSF $\beta$ may play critical roles during the peri-implantation process by regulating cytokine secretion of lymphocytes and by mediating the crosstalk between embryonic cells and endometrial stromal cells.

\section{Introduction}

In most mammals, the process of implantation, during which an early embryo must attach to and invade the maternal endometrium, is a critical step for successful pregnancy [1]. As the embryo is a semi-allograft to the maternal uterus, special immunotolerance must be established at the fetomaternal interface to allow the normal development of the fetus during the peri-implantation and subsequent pregnancy processes [2]. The mechanisms underlying the fetomaternal immune interaction are still not fully understood; however, it has been well demonstrated that cytokines locally produced and secreted by fetal and maternal lymphocytes play essential roles in the establishment of local immunosuppression [35].

Monoclonal nonspecific suppressor factor (MNSF) was originally identified as a specific cytokine that could moderate the immune response not only by inhibiting the proliferation of $\mathrm{T}$ and $\mathrm{B}$ cells $[6,7]$ but also by regulating cytokine secretion by $\mathrm{T}$ cells $[8,9]$. There are at least two subunits of MNSF, MNSF $\alpha$ and $\beta$. MNSF $\beta$ has been well characterized at the protein level and is responsible for 
the biological function of MNSF [10]. MNSF $\beta$ is a 133aa-secreted protein consisting of an ubiquitin-like (UbiL) domain and a ribosomal protein S30 domain, with the Ubi-L segment possessing the MNSF-like bioactivities [9]. Importantly, MNSF $\beta$ has been identified in association with implantation in mice: its expression was decreased at implantation sites but increased at interimplantation sites [11]. Furthermore, immunoneutralization of endometrial MNSF $\beta$ in vivo with a specific anti-MNSF $\beta$ antibody significantly inhibited mouse embryo implantation, potentially by disturbing fetomaternal immune tolerance, trophoblast invasion, or embryonic development [12], calling for the further investigation.

The local immunosuppression mediated by cytokines and the altered balance between Type- 1 and Type- 2 helper $\mathrm{T}$ cells (Th1/Th2 ratio) are thought to be important for the establishment of maternal-fetal tolerance during pregnancy, though the mechanisms are not fully clarified $[3,4,13]$. In addition, MNSF $\beta$ inhibits the secretion of interleukin-4 (IL4) by bone-marrow-derived mast cells and a cell line of type 2 helper $\mathrm{T}$ cells and also inhibits production of tumor necrosis factor-alpha (TNF $\alpha)$ in LPS-stimulated macrophages [14]. We hypothesised that, during the processes of implantation and subsequent pregnancy, MNSF $\beta$ produced at the interimplantation sites may be secreted and locally regulate the functions of lymphocytes at implantation sites.

The homology between mouse and human MNSF $\beta$ homologues is over $97.8 \%$ for both the nucleic acid and amino acid sequences (GenBank blast analysis). It would, therefore, be expected that human MNSF $\beta$ protein could be used to affect mouse lymphocytes. Since MNSF $\beta$ is not commercially available, we expressed MNSF $\beta$ in human cervical carcinoma (HCC-94) cell lines and examined the effects of the MNSF $\beta$-containing HCC-94 cell culture supernatants on the cytokine-secreting functions of mouse lymphocytes, enabling us to demonstrate paracrine actions of MNSF $\beta$ on lymphocytes in the absence of direct cell-cell interactions.

In vivo studies on early embryo development and implantation in mice are difficult due to the interferences from the complex intrauterine environment. Several in vitro models, including cocultures of human hatched blastocysts with endometrial stromal cell monolayers [15] and mouse day 4 blastocysts cocultured with intact uterine endometrium [16], are proven powerful tools to investigate the molecular mechanisms of early embryonic development and implantation. In the present study, we also determined the effect of anti-MNSF $\beta$ antibody on the in vitro development and implantation of mouse embryos using a coculture model of mouse day 3.5 embryos with endometrial stromal cells.

\section{Materials and Methods}

2.1. Animals and Cells. Adult ICR mice of 8-12 weeks old (female 25-30g, male 35-40 g) were purchased from the SIPPR/BK Laboratory Animal Company, Shanghai, China. All of the mice were caged at controlled temperature (approximately $22^{\circ} \mathrm{C}$ ) under a photoperiod of $14 \mathrm{~h}$ light: $10 \mathrm{~h}$ dark. All experiments were performed in full compliance with standard laboratory animal care protocols approved by the Institutional Animal Care Committee of Shanghai, Institute of Planned Parenthood Research. Adult female mice were mated with fertile males to achieve pregnancy, and day 1 of pregnancy was defined as the day of vaginal plug. The HCC-94 human cervical cell line was obtained from the cell bank of the Chinese Academy of Sciences in Shanghai. The cells were cultured routinely in RPMI 1640 medium with 10\% fetal bovine serum (FBS) (Gibco, USA). Human embryo fibroblasts (kindly provided by Dr. Sha Hongyin) were cultured in F10/Dulbecco's modified Eagle's medium (DMEM) (Gibco, USA) with 10\% FBS, and mouse uterine endometrial cells were isolated as previously described [17] and cultured in F-10/DMEM medium containing $10 \% \mathrm{FBS}$ at $37^{\circ} \mathrm{C}$ and $5 \% \mathrm{CO}_{2}$.

2.2. Construction of the MNSF $\beta$ Recombinant and siRNA Interference Expression Plasmids. The cDNA fragment encoding MNSF $\beta$ previously was purchased from the Proteintech Group Inc (BC033877) and subcloned into the pDsRed-N1 vector plasmid (Clontech Laboratories, Inc.) to construct the recombinant expression plasmid pDsRed-N1/MNSF $\beta$. The inserted MNSF $\beta$ cDNA and its encoding frame were confirmed by DNA sequencing and restriction analyses. This recombinant plasmid was expected to express MNSF $\beta$-DsRed fusion protein, which is marked with red fluorescence.

Four different siRNA interference sequences (P1, P2, P3, and P4) targeting human MNSF $\beta$ mRNA were designed according to its cDNA sequence (Gene ID: 2197) and synthesized by the Shanghai GeneChem Co., Ltd, Shanghai, China. Target messages of the MNSF $\beta$ mRNA about four interference sequences were as follows: P1: AAGAGGCGAATGCAGTACAAC; P2: GCCCACCTTTGGGAAGAAGAA; P3: GTCGCCCAGATCAAAGATCAT; P4: TCTGGAAGTAGCAGGCCGCAT. The pDC316-EGFP-U6 vector (BIOYONG Scientific Limited, Beijing, China) was used to construct the corresponding plasmids to express the short hairpin RNA (shRNA) targeting the human MNSF $\beta$ mRNA.

According to the instructions provided by the manufacturer, the constructed expression plasmid containing one of each of the four interference sequences, labeled as P1, P2, P3, or P4, was transfected into HCC-94 cells with Lipofectamine 2000 Transfection Reagent (Invitrogen). Total RNA was extracted from the cells, and the MNSF $\beta$ mRNA levels were detected by RT-PCR to screen for the most effective interference sequence. The sequences of primers were as follows: MNSF $\beta, 5^{\prime}$-ACTCCATCTTCGCGGTAGC- $3^{\prime}$ (sense) and $5^{\prime}$ GGAGCACGACTTGATCTTCC-3' (antisense) (170 bp); $\beta$ actin, $5^{\prime}$-TCT CCT TAA TGT CAC GCA CGA-3' (sense) and $5^{\prime}$-ACA ATG AGC TGC GTG TGG CT-3' (antisense) (395 bp).

\subsection{Transfection of MNSF $\beta$ Constructs into HCC-94 Cells and Assessment of Resultant Expression Levels. In a $35 \mathrm{~mm}$ diameter Petri cell culture dish (Corning, Invitrogen, USA), $1 \times 10^{6}$ HCC-94 cells per well were seeded in $2 \mathrm{~mL}$ RPMI 1640 media supplemented with 10\% FBS and incubated}


at $37^{\circ} \mathrm{C}, 5 \% \mathrm{CO}_{2}$ until $70-80 \%$ confluence. The HCC94 cells were then transfected with one of four different plasmids: (1) recombinant pDC316-EGFP-U6 plasmid containing the most effective interference sequence targeting the MNSF $\beta$ mRNA (siRNA), (2) recombinant pDC316EGFP-U6 plasmid containing the unrelated interference sequence of MNSF $\beta$ mRNA (NC for siRNA, as the control), (3) recombinant $\mathrm{pDsRed-N1/MNSF} \beta$ expression plasmids $(\mathrm{MNSF} \beta$ ), and (4) pDsRed-N1 vector plasmids (NC for MNSF $\beta$, as the control). The transfection procedure was as follows: $2 \mu \mathrm{g}$ plasmid DNA was suspended in $200 \mu \mathrm{L}$ OptiMEM I media (Solution A), and $8 \mu$ L Lipofectamine reagent was diluted in $200 \mu \mathrm{L}$ Opti-MEM I media (Solution B); then Solution A and B were mixed gently. The mixture was added to the cultured HCC-94 cells and incubated at $37^{\circ} \mathrm{C}$ and $5 \% \mathrm{CO}_{2}$. After $24 \mathrm{~h}$, the fluorescence of these cells was observed under a fluorescence microscope (Nikon $50 \mathrm{i}$, Japan) to calculate the transfection efficiency. If the transfection efficiency reached 60-70\%, the HCC-94 cells and their cell culture supernatants were collected for each of the different experimental groups.

2.4. Detection of MNSF $\beta$ Protein Levels Expressed by Transfected HCC-94 Cells by Western Blot Analysis. The rabbit anti-mouse MNSF $\beta$ polyclonal antibody was prepared and its specificity previously demonstrated in our laboratory [12]. To detect the MNSF $\beta$ protein expression levels in transfected HCC-94 cells, $150 \mu \mathrm{L}$ of protein lysis buffer (Beijing ComWin Biotech Co., Ltd., China) was added to each well. The cellular lysate was centrifuged at $12,000 \mathrm{~g}$ for $10 \mathrm{~min}$ at $4^{\circ} \mathrm{C}$, and the total protein concentration of the cellular lysate was determined by the Bradford assay (BioRad, Hercules, Calif, USA). The supernatants were placed into a Green Bird dialysis bag (MWCO: Nominal 700 Flat Width: $25 \mathrm{~mm}$, Shanghai Green Bird Science \& Technology Development Co., Ltd., China) with a $0.22 \mu \mathrm{m}$ pore size and dialyzed overnight against distilled water. The dry powder obtained by freeze-drying (4.5 Liter Benchtop Freeze Dryer Systems, Labconco Corporation, USA), was subsequently dissolved in PBS, and the total protein concentration was also determined by the Bradford Assay. The protein samples were resolved by SDS-PAGE (12\% acrylamide) with 30 ug of total protein for each sample (cell lysate and supernatant from each group of transfected cells) loaded per lane. Resolved proteins were transferred to nitrocellulose membranes (Millipore Corporation, USA). Following incubation overnight at $4^{\circ} \mathrm{C}$ in a blocking solution (Tris-buffered saline solution with $5 \%$ low fat milk) to block nonspecific binding sites, the membranes were incubated with the rabbit anti-mouse MNSF $\beta$ polyclonal antibodies at a 1:100 dilution for $2 \mathrm{~h}$ at room temperature and then incubated with alkaline phosphatase-labeled goat anti-rabbit antibodies (Invitrogen Zymed Laboratories, USA) at a 1:5000 dilution for $1 \mathrm{~h}$ at room temperature. The immunoreactive complexes on the membrane were visualized by staining for 3 min with a PhosphaGLO AP Substrate kit (KPL, Gaithersburg, Md, USA) according to the manufacturer's protocol. As the sample loading control, $\beta$-actin level of each sample was detected by a rabbit anti- $\beta$-actin polyclonal antibody (Cell Signaling Technology, Ltd. Inc., USA) at a 1:1000 dilution.

2.5. Preparation of Mouse Peripheral Blood Lymphocytes. Adult ICR male mice were anesthetized routinely with Sumianxin (Military Veterinary Institute, Academy of Military Medical Sciences, Changchun, China). Blood was collected from the heart, and heparin solution anticoagulant (Jilin Huakang Pharmaceutical Co., Ltd.) was added to a final concentration of $15 \mathrm{IU} / \mathrm{mL}$. The collected mouse peripheral blood was then mixed with erythrocyte lysis buffer (Applygen Technologies Inc.) in a ratio of $1 \mathrm{~mL}$ blood $/ 3 \mathrm{~mL}$ lysis buffer, the mixture incubated for $10 \mathrm{~min}$ at room temperature and subsequently centrifuged at $1500 \mathrm{~g}$ for $5 \mathrm{~min}$. The precipitate was suspended with $1 \mathrm{~mL}$ erythrocyte lysis buffer, incubated for $10 \mathrm{~min}$ at room temperature and centrifuged at $1500 \mathrm{~g}$ for $5 \mathrm{~min}$. The resultant precipitate containing white cells was resuspended with $1.5 \mathrm{~mL}$ normal saline, and mouse lymphocytes were isolated following manufacturer's instructions. In brief $2 \mathrm{~mL}$ Ficoll-Hypaque lymphocyte separation fluid (Tianjin Hao Yang Biological Manufacture Co., Ltd., China) was measured into a $10 \mathrm{~mL}$ centrifuge tube, $1.5 \mathrm{~mL}$ total cell solution was applied on top, and the whole centrifuged at $2000 \mathrm{~g}$ for $15 \mathrm{~min}$. The lymphocyte layer was collected and transferred into $5 \mathrm{~mL}$ of PBS (Gibco, USA), vortexed gently, and centrifuged at $2000 \mathrm{~g}$ for $10 \mathrm{~min}$. The precipitate contained the mouse lymphocytes. The primary lymphocytes were cultured in RPMI Medium 1640 with $10 \% \mathrm{FBS}$ at $37^{\circ} \mathrm{C}$ and $5 \% \mathrm{CO}_{2}$.

2.6. Treatment of Mouse Lymphocytes by HCC-94 Cell Culture Supernatants. The prepared lymphocytes were inoculated in a 24-well plate $(1 \mathrm{~mL} /$ well $)$ at a density of $5 \times$ $10^{4}$ cells $/ \mathrm{mL}$ and cultured in RPMI 1640 medium with $10 \%$ FBS for 24 hours, after which the lymphocytes were harvested from individual wells, centrifuged at $1000 \mathrm{~g}$ for $5 \mathrm{~min}$, and supernatants discarded. The mouse lymphocytes were resuspended in culture medium from the different transfected HCC-94 cell supernatants $\left(6 \times 10^{4}\right.$ cells $/ 500 \mu \mathrm{L}$ supernatant/well) and inoculated into wells of a 24-well plate. Triplicate wells were performed for each different transfected cell supernatant. Mouse fibroblast or lymphocyte culture supernatants were used as additional controls. Media were collected at different times $(6 \mathrm{~h}, 12 \mathrm{~h}$ and $24 \mathrm{~h})$ of culture. Supernatants were collected, centrifuged at $1000 \mathrm{~g}$ for $10 \mathrm{~min}$, and stored at $-20^{\circ} \mathrm{C}$ for further analysis.

\subsection{Detection of TNF $\alpha$ and IL-4 Concentrations in Mouse} Lymphocyte Culture Supernatants by ELISA. The concentrations of IL- 4 and TNF $\alpha$ in the mouse lymphocyte culture supernatants were detected using mouse IL-4 and TNF $\alpha$ cytokine ELISA Kits nos. (F10810 and F11630) (Shanghai Westang Bio-Tech Co., Ltd, Shanghai, China). The secretion levels of IL- 4 and TNF $\alpha$ were evaluated on ELx800 Absorbance Microplate Reader (BioTek Instruments, Inc.). Each sample was analyzed in duplicate, with diluent used as the blank. The blank would have been unconditioned culture medium, diluted to the same extent with diluents. The 
absorbance at wavelength of $450 \mathrm{~nm}$ (A450) was measured, and the mean of the blank values was subtracted from all experimental values. To draw the standard curve, A450 values of the standards supplied with the kits were detected at concentrations of $500,375,250,187.5,125,94,62,5,47$, 31.25 , and $0 \mathrm{pg} / \mathrm{mL}$, and IL- 4 and TNF $\alpha$ concentrations in the supernatants were calculated from their A450 values according to their corresponding standard curve.

\subsection{Establishment of a Mouse Embryo and Endometrial Cell} Coculture Model. Uterine tissues were collected from day 3.5 pregnant mice, immediately following sacrifice by cervical dislocation. Mouse embryos were flushed from each uterus with sterile saline. While the inner cell mass and blastocoele were both clear under the dissecting microscope, blastulas were selected and cultured temporarily in DMEM/F-10 medium for coculture use. After embryo collection, the uterine horns were removed, and the uterus cut open and digested with $0.1 \%$ trypsin applied to the luminal surface for 30 minutes at $37^{\circ} \mathrm{C}$ and $5 \% \mathrm{CO}_{2}$ in an incubator. The digestion was terminated with DMEM/F10 medium containing 10\% FBS, and a mix of epithelial and stromal cells were gently scraped off with a rubber instrument. Cell viability was determined by $0.4 \%$ trypan blue dye staining, and $3 \times 10^{6}$ live endometrial cells were inoculated in a culture dish of $3 \mathrm{~cm}$ in diameter and incubated at $37^{\circ} \mathrm{C}$ and $5 \% \mathrm{CO}_{2}$. Medium was removed after $24 \mathrm{~h}$ to eliminate nonadherent cells, adherent cells removed by trypsinization and washed, and $5 \times 10^{6}$ live cells subcultured into a $6 \mathrm{~cm}$ diameter Petri dish. After these cells were passaged twice; these endometrial stromal cells were identified by immunofluorescence assays and used to establish the coculture model with mouse blastocysts. Day 3.5 mouse blastocysts were transferred onto prepared monolayers of endometrial cells with a mouse egg retrieval apparatus (made in our laboratory), and this time point was recorded as day 1 . The medium was changed every 3 days, and the hatching and spreading growth of the cocultured mouse blastocysts on endometrial cells were observed daily under an inverted microscope.

2.9. Detection of MNSF $\beta$ Protein Expressed by Mouse Blastocysts and Endometrial Cells by Immunochemistry and Immunofluorescence Assays. Mouse endometrial stromal cells were fixed in $4 \%$ paraformaldehyde for $10 \mathrm{~min}$ at room temperature and washed three times with PBS. To block the nonspecific immune reaction, the cells were incubated in $10 \%$ goat serum in PBS for $30 \mathrm{~min}$ at room temperature followed by incubation with the rabbit anti-MNSF $\beta$ polyclonal antibody $(1: 100)$ in blocking solution at $37^{\circ} \mathrm{C}$ for 2 hours. Cells were then washed in PBS three times and incubated with Biotin-SP-conjugated donkey anti-rabbit IgG antibody (Proteintech Company) (1:200 in blocking solution) at $37^{\circ} \mathrm{C}$ for 1 hour. After washing, the cells were incubated for $30 \mathrm{~min}$ at $37^{\circ} \mathrm{C}$ with Streptavidin-HRP (Proteintech Company) diluted 1:200 in blocking solution, and immunoreactive complexes were visualized with a DAB color kit (Wuhan Boster Bio-engineering Ltd. Co., China). The resultant staining was recorded by photography under a bright field microscope (Nikon TE2000-U, Japan). The expression of MNSF $\beta$ protein in the mouse embryo was detected by an immunofluorescence assay in which the rabbit anti-MNSF polyclonal antibody was used as the primary antibody, and Alexa Fluor 568-labeled donkey anti-rabbit IgG $(\mathrm{H}+\mathrm{L})$ (Invitrogen, USA) was applied as the secondary antibody at a dilution of $1: 5000$ in 10\% goat serum in PBS. Nuclei were counterstained with $1 \mathrm{ug} / \mathrm{mL}$ propidium iodide in double-distilled water at room temperature for $5 \mathrm{~min}$ in the dark. The results were observed and recorded using fluorescence microscopy (Nikon TE2000-U, Japan).

2.10. Treatment of Cocultured Mouse Embryo and Endometrial Cells by Anti-MNSF $\beta$ Antibody. Rabbit anti-MNSF $\beta$ serum was heat inactivated at $56^{\circ} \mathrm{C}$ for 30 minutes and diluted $10 \%(\mathrm{~V} / \mathrm{V})$ in DMEM/F-10 medium with 5\% FCS. Mouse endometrial cells were inoculated into a 96 -well microplate $\left(3 \times 10^{4}\right.$ cells per well) and incubated at $37^{\circ} \mathrm{C}$ and $5 \% \mathrm{CO}_{2}$ for 24 hours when the culture medium was replaced by medium containing $10 \%$ rabbit anti-MNSF $\beta$ sera (preimmune serum was used as control). Following 1 hour incubation, day 3.5 mouse embryos were transferred onto the endometrial cells ( 6 embryos per well): this time point was designated as day 1 of coculture. On day 4 of coculture, the culture medium was replaced by DMEM/F-10 medium with $10 \%$ FBS. Development of the mouse embryos was observed microscopically and photographed with or without immunofluorescent staining on days $1,3,5,7$, and 9 .

2.11. Statistical Analysis. All ELISA data were analyzed using the SPSS13.0 software (SPSS Inc., Chicago, ILL, USA). Data for each treatment at a specific timepoint was presented as mean \pm SD of three separate experiments. For comparisons of means among the treatments at a specific timepoint, ANOVA analysis was used. If the ANOVA showed significant difference, further multiple comparisons were performed with the Bonferroni method, which was considered significant at a level of $P<0.05$.

\section{Results}

3.1. MNSF $\beta$ Protein Was Abundantly Expressed by In Vitro Cultured Nontransfected HCC-94 Cells and Mouse Endometrial and Embryonic Cells. Both human and mouse MNSF $\beta$ consist of 133 amino acids, and their amino acid sequences are almost the same for except 3 residues (Figure 1); therefore, the rabbit antisera against mouse MNSF $\beta$ were used to detect both human and mouse MNSF $\beta$ in the present study. Immunohistochemistry and western blotting demonstrated that MNSF $\beta$ protein was abundantly expressed by HCC-94 cells and mouse uterine endometrial stromal cells (Figure 2, HCC, En) and no positive signal was detected in the mouse lymphocytes (Figure 2, Lym). In addition, the isolated mouse endometrial cells were identified by immunofluorescence, and the results showed that more than $90 \%$ passage-cultured mouse endometrial cells were classified as stromal cells (see Figure 1 in Supplementry Material available online at doi: $10.5402 / 2011 / 186541)$. 
CLUSTAL 2.0.12 multiple sequence alignment

\begin{tabular}{|c|c|c|c|}
\hline hMNSF $\beta$ & \multicolumn{2}{|c|}{ MQLFVRAQELHTFEVTGQETVAQIKAHVASLEGIAPEDQWLLAGAPLEDEATLGQCGVE } & 60 \\
\hline $\operatorname{mMNSF} \beta$ & \multicolumn{2}{|c|}{$\begin{array}{l}\text { MQLFVRAQELHTLEVTGQETVAQIKDHVASLEGIAPEDQWLLAGSPLEDEATLGQCGVE } \\
* * * * * * * * * * * * * * *: * * * * * * * * * * * * * * * *: * * * * * * * * * * * * * * * * * * * * * * * * * * * * * * * * * * * * * * * * * *\end{array}$} & 60 \\
\hline $\mathrm{hMNSF} \beta$ & \multicolumn{2}{|c|}{ ALTTLEVAGRMLGGKVHGSLARAGKVRGQTPKVAKQEKKKKKTGRAKRRMQYNRRFVNW } & 120 \\
\hline $\operatorname{mMNSF} \beta$ & \multicolumn{2}{|c|}{$\begin{array}{l}\text { ALTTLEVAGRMLGGKVHGSLARAGKVRGQTPKVAKQEKKKKKTGRAKRRMQYNRRFVNW } \\
* * * * * * * * * * * * * * * * * * * * * * * * * * * * * * * * * * * * * * * * * * * * * * * * * * * * * * * * * * * * * * * * * * * * * * * * * * * * * * * *\end{array}$} & 120 \\
\hline hMNSF $\beta$ & PTFGKKKGPNANS & 133 & \\
\hline $\operatorname{mMNSF} \beta$ & $\begin{array}{l}\text { PTFGKKKGPNANS } \\
* * * * * * * * * * * * * * * *\end{array}$ & 133 & \\
\hline
\end{tabular}

FIGURE 1: Amino acid sequence alignment of human and mouse MNSF $\beta$. Both human and mouse MNSF $\beta$ proteins consist of 133 amino acids, and their sequences share $97.8 \%$ homology.
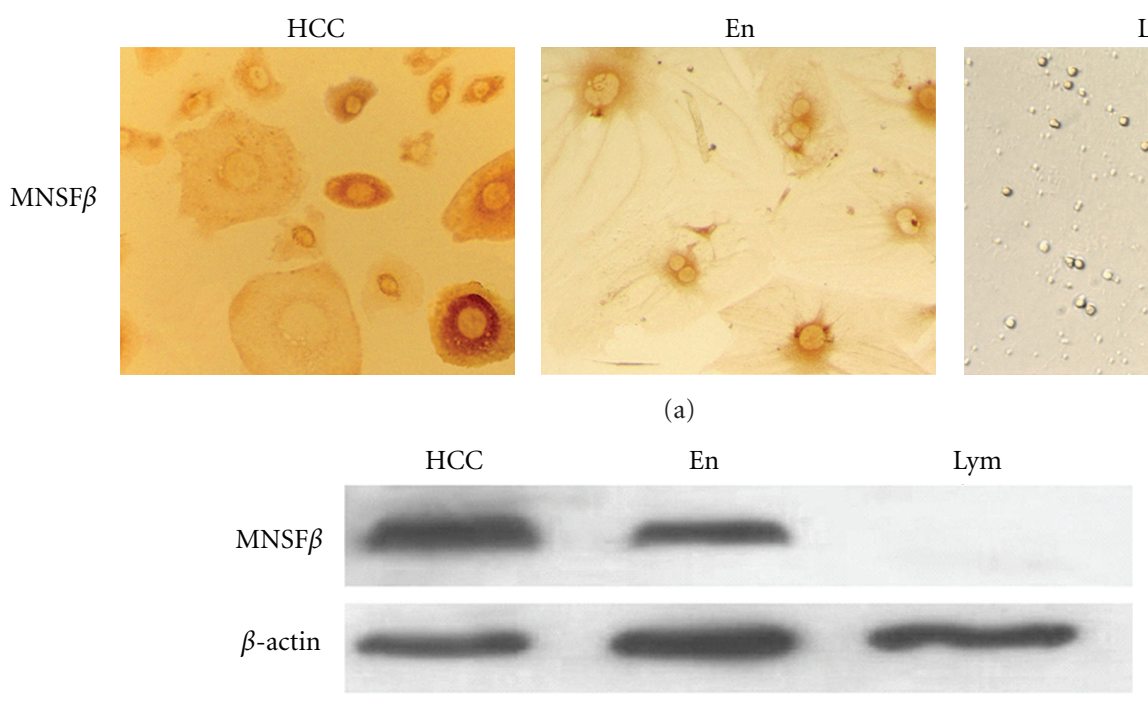

(b)

FIGURE 2: Determination of MNSF $\beta$ protein in HCC-94 cells, mouse endometrial cells, and lymphocytes by immunohistochemistry and western blotting analyses. (a) Immunohistochemical staining of MNSF $\beta$ protein; (b) western blot detection of MNSF $\beta$ protein. HCC: HCC94 cells; En: mouse endometrial stromal cells; Lym: peripheral blood lymphocytes. $\beta$-actin was use as sample-loading reference in the western blotting detection.

Immunofluorescent staining of the cocultured mouse embryo and endometrial cells showed that, throughout the coculture (days 1-7), both the embryonic and the endometrial stromal cells stained for MNSF $\beta$, with the staining being more intense at the interface between the embryos and the endometrial stromal cell monolayer (Figure 3).

3.2. MNSFß mRNA Expression Level of HCC-94 Cells Was Differentially Regulated by Transfection with pDC316-EGFPU6/MNSF $\beta-P 1$ or $p D s R e d-N 1 / M N S F \beta$. Four recombinant interference plasmids, pDC316-EGFP-U6/MNSF $\beta$-P1, P2, $\mathrm{P} 3$, and $\mathrm{P} 4$, were constructed and separately transfected into HCC-94 cells. The relative expression levels of MNSF $\beta$ mRNA were determined by semiquantitative RT-PCR analysis using the $\beta$-actin mRNA as reference.

The results showed a specific band of MNSF $\beta$ mRNA in HCC-94 cells without plasmid transfection (Figure 4(b), lane 1), indicating endogenous MNSF $\beta$ mRNA expression in HCC-94 cells; the highest level of exogenous MNSF $\beta$ mRNA expression was detected in HCC-94 cells transfected with pDsRed-N1/MNSF $\beta$ (Figure 4(b), lane 2); endogenous expression was effectively inhibited by transfection with pDC316-EGFP-U6/MNSF $\beta$-P1 (Figure 4(b), lane 3). There is no significant difference in MNSF $\beta$ mRNA expression levels in HCC-94 cells transfected by the control plasmids pDC316-EGFP-U6/MNSF $\beta$-NC (Figure 4(b), lane 4) or pDsRed-N1 (Figure 4(b), lane 5), which compared with non-treated HCC-94 cells.

3.3. MNSF $\beta$ Protein Secretion Levels of HCC-94 Cells Were Differentially Regulated by Overexpression and RNA Interference of MNSF $\beta$. MNSF $\beta$ protein concentrations in different HCC-94 cell culture supernatants were evaluated by western blotting analysis. Native MNSF $\beta$ protein (133 aa) and MNSF $\beta$-DsRed fusion protein (363 aa) were detected as specific bands at around $14-\mathrm{kDa}$ and $40-\mathrm{kDa}$ apparent 

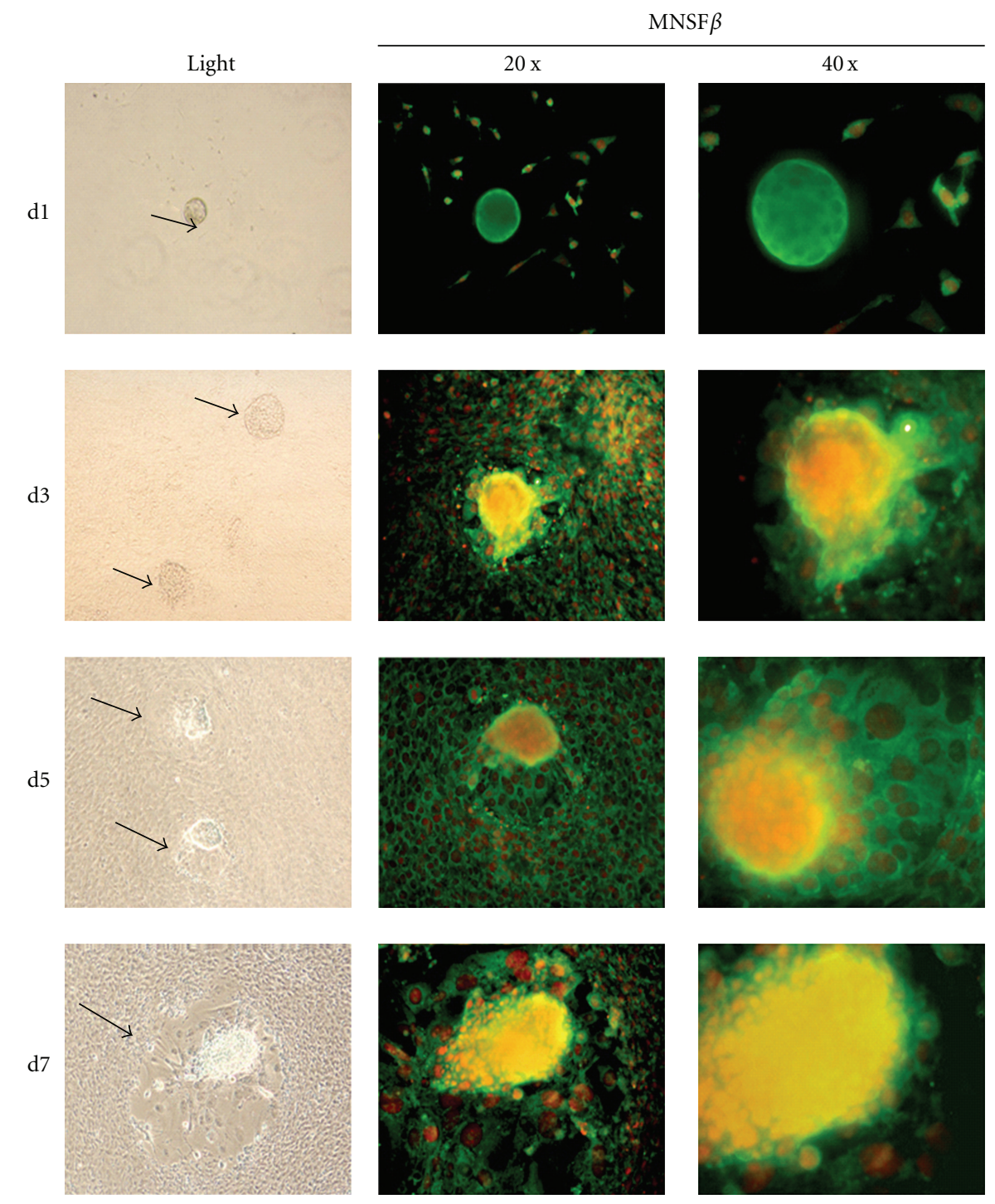

FIGURE 3: Examination of MNSF $\beta$ protein in cocultured mouse embryos and endometrial cells by immunofluorescence analysis. MNSF $\beta$ protein staining signals were detected both in mouse embryos and endometrial cells throughout the coculture process. Column 1: observed under white light; Columns 2 and 3: microscopic photos of fluorescence. Columns 1 and 2 were taken under the 20x objective lens, and Column 3 was taken under the 40x objective. d1: the day that mouse embryos of day 3.5 pregnancy were added into the mouse endometrial cells culture; d3, d5, and d7: the third, fifth, and seventh day of the coculture of mouse embryos and endometrial cells.

molecular masses as expected, respectively, (Figure 4(c)). The native MNSF $\beta$ protein secretion level of HCC-94 cells transfected with the pDC316-EGFP-U6/MNSF $\beta$-P1 (Figure 4(c), lane 3), was considerably decreased compared to that of HCC-94 cells transfected with the pDC316EGFP-U6/MNSF $\beta$-NC (Figure 4(c), lane 2) or pDsRed-N1 (Figure 4(c), lane 4), whereas abundant native MNSF $\beta$ and recombinant MNSF $\beta$-DsRed fusion proteins were detected in cell culture supernatants of HCC-94 transfected with the pDsRed-N1/MNSF $\beta$ (Figure 4(c), lane 5). Human embryo fibroblasts without MNSF $\beta$ expression were used as a control: no secreted MNSF $\beta$ was detected in their culture supernatants (Figure 4(c), lane 1).
3.4. MNSF $\beta$ Induced the Secretion of IL-4 and Inhibited the Secretion of TNF $\alpha$ from Mouse Lymphocytes. Approximately $1.7 \times 10^{6}$ lymphocytes were isolated from $1 \mathrm{~mL}$ mouse peripheral blood. These were incubated with the different cell culture supernatants described above and the concentrations of IL- 4 and TNF $\alpha$ determined by ELISA after 6, 12, and 24 hours of incubation. Only the HCC-94 culture supernatant with overexpressed MNSF $\beta$ protein significantly induced secretion of IL-4 from mouse lymphocytes. Other HCC94 culture supernatants did not have a significant effect on IL-4 secretion from lymphocytes (Figures 5(a) and 5(c)); however, after the incubation of lymphocytes with the culture supernatant of HCC-94 cells transfected with the 


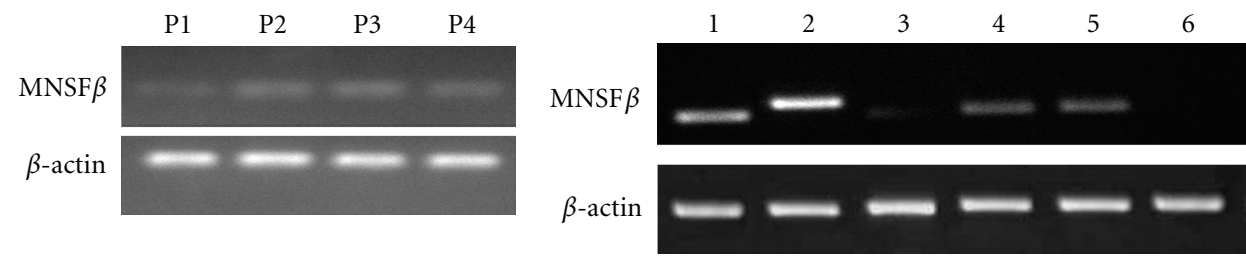

(a)

(b)

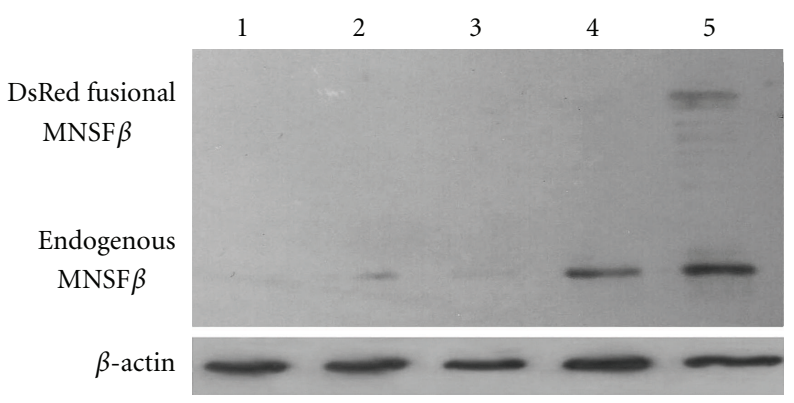

(c)

Figure 4: Differential regulation of MNSF $\beta$ gene expression in HCC-94 cells by RNA interference and overexpression. (a) Identification of an effective RNA interference sequence targeting the MNSF $\beta$ mRNA by RT-PCR analysis. Total RNA were extracted from the transfected cells for RT-PCR analysis, and P1 was demonstrated to be the most effective RNA interference sequence of MNSF $\beta$ mRNA. (b) RT-PCR detection of MNSF $\beta$ mRNA expression levels in HCC-94 cells transfected with different plasmids. Lane 1: total RNA extracted from HCC-94 cells without plasmid transfection, Lane 2: total RNA extracted from HCC-94 cells transfected with pDsRed-N1/MNSF $\beta$, Lane 3: total RNA extracted from HCC-94 cells transfected with pDC316-EGFP-U6/MNSF $\beta$-P1, Lane 4: total RNA extracted from HCC-94 cells transfected with pDsRed-N1 (as the overexpression control), Lane 5: total RNA extracted from HCC-94 cells transfected by pDC316-EGFP-U6/MNSF $\beta$ NC (as the siRNA interference control), and Lane 6: total RNA extracted from human fibroblasts (as negative control). (c) Western blotting analysis of MNSF $\beta$ protein in culture supernatants of HCC-94 cells transfected with different plasmids. Lane 1: supernatants of human fibroblasts (as negative control), Lane 2: supernatants of HCC-94 cells transfected with pDC316-EGFP-U6/MNSF $\beta$-NC, Lane 3: supernatants of HCC-94 cells transfected with pDC316-EGFP-U6/MNSF $\beta$-P1, Lane 4: supernatants of HCC-94 cells without plasmid transfection, and Lane 5: supernatants of HCC-94 cells transfected with pDsRed-N1/MNSF. $\beta$-actin (lower panel of (b, c)) was used as reference both in the RT-PCR and western blotting analysis.

RNA interference plasmid, the secretion of TNF $\alpha$ from lymphocytes was sharply increased (Figures 5(b) and 5(d)).

\subsection{The Effects of MNSF $\beta$ on Secretion of $I L-4$ and} TNF $\alpha$ from the Mouse Lymphocytes Were Neutralized by Anti-MNSF $\beta$ Antibodies. To further validate the effects of MNSF $\beta$ on IL- 4 and TNF $\alpha$ secretion, immunoneutralization was performed. HCC-94 supernatants with overexpressed MNSF $\beta$ were incubated with rabbit anti-MNSF $\beta$ sera or preimmune rabbit sera (as control) for 1 hour at room temperature and then added into the mouse lymphocyte culture and incubated for 6,12 , and 24 hours. The concentrations of IL- 4 and TNF $\alpha$ were subsequently determined by ELISA. It was clear that prior immunoneutralization of $\operatorname{MNSF} \beta$ reduced the previously demonstrated increased secretion of IL-4 from mouse lymphocytes (Figure 5(e)), and the inhibitory effect of MNSF $\beta$ on the secretion of TNF $\alpha$ was also lost (Figure 5(f)), indicating that the effects on the secretion of IL-4 and TNF $\alpha$ were specific to MNSF $\beta$, not the fused DsRed protein.

3.6. In Vitro Inhibitory Effect of Anti-MNSF $\beta$ Antibody on the Implantation of Mouse Embryos. Unhatched mouse embryos from day 3.5 pregnancy were collected and cocultured onto the mouse endometrial stromal cells. On day 3 of coculture, embryos underwent the hatching process normally; on day 5 , these hatched blastocysts started to adhere to and invade the endometrial cells (Figure 6(a)), and, on day 7, blastocysts had spread across the endometrial cell layer and continued to grow until they contacted one another (Figure 6(a)). Meanwhile, some endometrial stromal cells around the embryonic cells increased in size, with a nuclear volume increase, similar to that seen during the in vivo phenomenon of decidualization during embryo implantation (data are not shown).

Since both the mouse embryonic and the endometrial cells expressed MNSF $\beta$, we, therefore, determined whether the effects were mediated by MNSF $\beta$ by immunoneutralization with preimmune sera used as control. Following treatment with preimmune sera, the mouse embryo developed normally on the endometrial cells in vitro as above (Figure 6(a)); however, following treatment with antiMNSF $\beta$ antisera, there was disturbance of the hatching and invasion of the embryos. These retained a complete zona pellucida throughout the in vitro coculture process (Figure 6(b)), indicating that MNSF $\beta$ protein is essential for hatching and, hence, for mouse embryo implantation. 


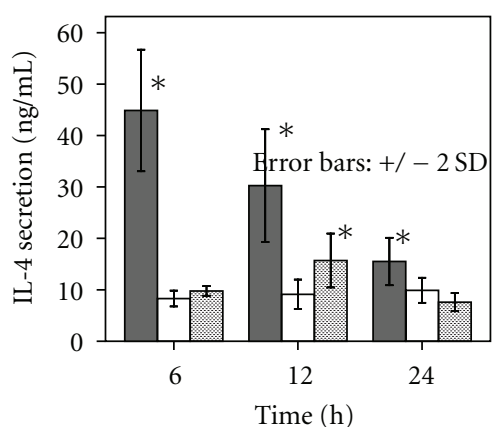

$\square$ MNSF $\beta$

NC for MNSF $\beta$

HCC-94

(a)

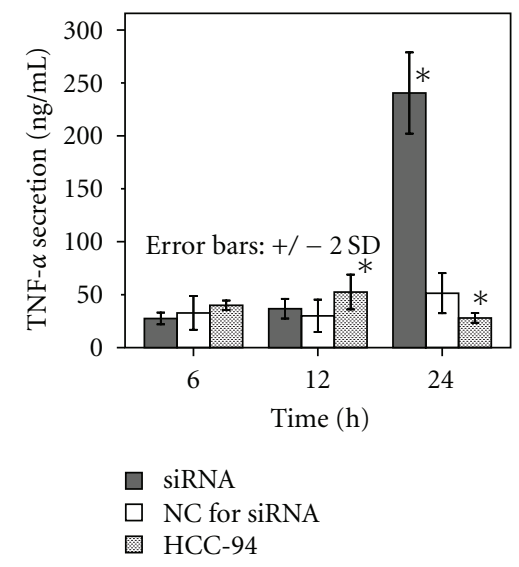

(d)

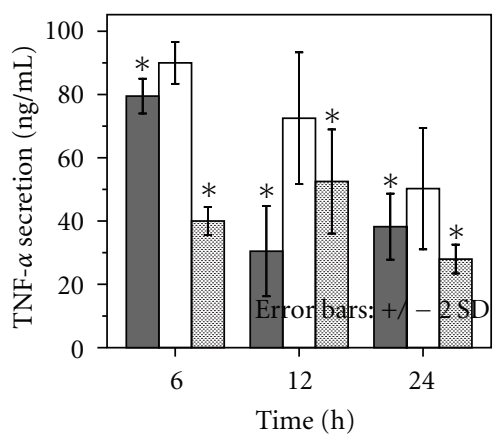

$\square$ MNSF $\beta$
NC for MNSF $\beta$
HCC-94

(b)

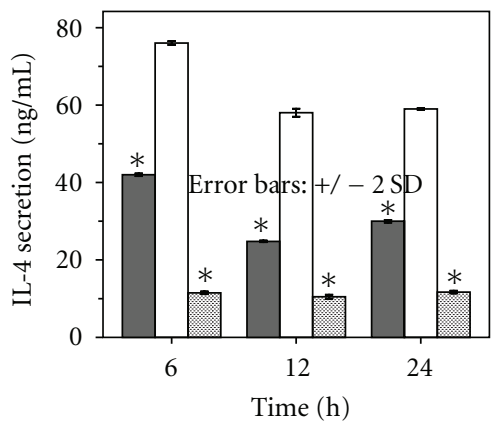

MNSF $\beta$ + antibody

MNSF $\beta+$ preimmunal

Antibody

(e)

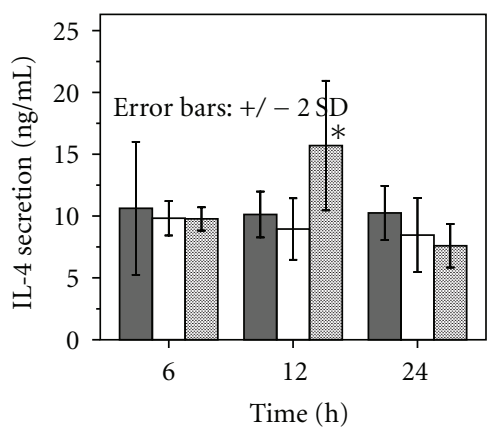

siRNA

NC for siRNA

HCC-94

(c)

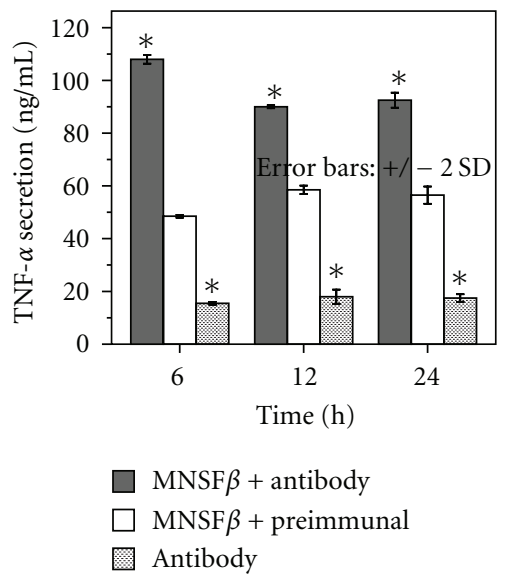

(f)

FIGURE 5: Action of culture supernatants from the HCC-94 cells, treated with MNSF $\beta$ overexpression, siRNA, or immunoneutralizing action of anti-MNSF $\beta$, on the secretion of IL-4 and TNF $\alpha$ from mouse lymphocytes. (a, c, e) IL- 4 concentrations in mouse lymphocytes culture supernatants detected by ELISA. (b, d, f) TNF $\alpha$ concentrations in mouse lymphocyte culture supernatants detected by ELISA. The timepoint when HCC-94 cells culture supernatants were added into the mouse lymphocytes culture was designated as 0 , and lymphocyte culture supernatants were sampled at 6,12, and 24 hours, respectively. MNSF $\beta$ : lymphocytes cultured in supernatant of HCC-94 cells transfected with pDsRed-N1/MNSF $\beta$; NC for MNSF $\beta$ : lymphocytes cultured in supernatant of HCC-94 cells transfected with pDsRed-N1; HCC-94: lymphocytes cultured in supernatant of HCC-94 cells without plasmid transfection (as negative control); siRNA: lymphocytes cultured in supernatant of HCC-94 cells transfected with pDC316-EGFP-U6/MNSF $\beta$-P1; "NC for siRNA": lymphocytes cultured in supernatant of HCC-94 cells transfected with pDC316-EGFP-U6/MNSF $\beta$-NC. MNSF $\beta$ + antibody: lymphocytes cultured in supernatant of HCC-94 cells transfected with pDsRed-N1/MNSF $\beta$ that were beforehand incubated with anti-MNSF $\beta$ antibody; "MNSF $\beta+$ preimmune": lymphocytes cultured in supernatant of HCC-94 cells transfected with pDsRed-N1/MNSF $\beta$ that were previously incubated with rabbit preimmune sera (control); Antibody: only rabbit anti-MNSF $\beta$ sera added to the mouse lymphocytes culture (control). Asterisks $\left(^{*}\right.$ ) indicate the significance $(P<0.05)$ in comparison with "NC for $\operatorname{MNSF} \beta$ " (a, b), "NC for siRNA" $(c, d)$, and “MNSF $\beta+$ preimmune" $(e, f)$.

\section{Discussion}

This study demonstrates a stimulatory effect of MNSF $\beta$ on the secretion of IL-4 from mouse lymphocytes, as well as an inhibitory effect on their secretion of TNF $\alpha$. Moreover, the results of the in vitro experiments using coculture model of mouse embryo and endometrial stromal cells to mimic embryo implantation in mice also showed that anti-MNSF $\beta$ antibody significantly inhibited embryo implantation (specifically hatching from the zona pellucida), consistent with and further defining the results of the in vivo experiments we previously reported [12].
MNSF $\beta$ was first identified as a potentially novel implantation related factor by Nie et al. [11], based on the differential expression of MNSF $\beta$ between the implantation and interimplantation sites during the mouse embryo implantation process. It was reported that, while MNSF $\beta$ protein disappeared from the endometrial stroma at implantation sites, it was abundantly expressed at interimplantation sites around the precise time of implantation in mice [11]. We subsequently carried out an in vivo loss-of-function experiment of MNSF $\beta$ by using its specific antibody in our previous study to determine whether or not MNSF $\beta$ was essential for mouse embryo implantation. Immunoneutralization of 

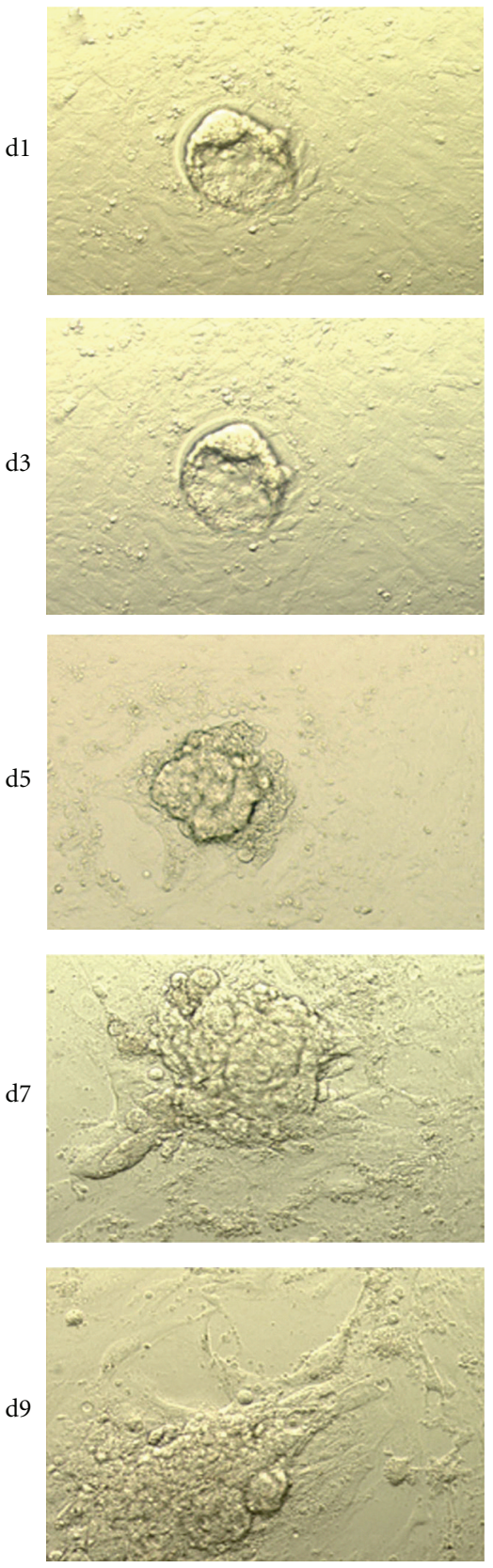

(a)
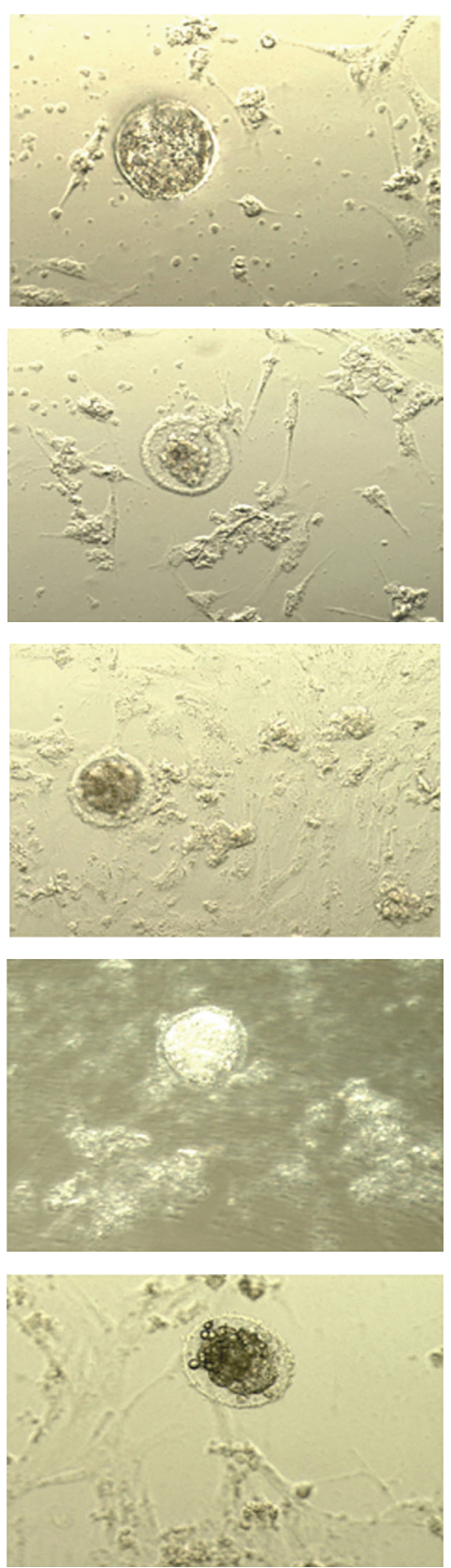

(b)

Figure 6: The effect of anti-MNSF $\beta$ antibody on in vitro implantation of mouse embryo onto the cocultured endometrial cells. (a) cocultured mouse embryo and endometrial cells treated by rabbit $10 \%$ preimmune sera (as a control); (b) cocultured mouse embryo and endometrial cells treated with $10 \%$ rabbit anti-MNSF $\beta$ antisera. All photomicrographs were taken under a 40x objective.

endometrial MNSF $\beta$ significantly inhibited mouse embryo implantation in vivo [12], indicating that MNSF $\beta$ protein plays critical roles in mouse embryo implantation.

During the implantation process, at the embryoendometrial interface, interaction between embryonic cells and endometrial stromal cells (which differentiate to become decidual cells) must be established. It has also been clearly demonstrated that blood lymphocytes infiltrate the endometrium, particularly during physiological and pathological processes, including embryo implantation and inflammation [18]. Furthermore, it has been suggested that IL-4, IL-6, and IL-10 may have protective effects on the establishment and maintenance of immunotolerance at the fetomaternal interface during the implantation and pregnancy processes, whereas TNF $\alpha$, IL-2, and IFN $\gamma$ may be inhibitory $[5,19]$. Thus, we hypothesized that, during embryo implantation, intrauterine MNSF $\beta$ might play essential roles not only by regulating the interaction between the 
embryonic and endometrial cells but also by regulating the cytokine secretion of infiltrated blood lymphocytes.

In the present study, to determine the paracrine actions of MNSF $\beta$ on the secretion of IL- 4 and TNF $\alpha$ from blood lymphocytes without direct interaction between the MNSF $\beta$ secreting cells and lymphocytes, an in vitro model was established using secretions from modified HCC-94 cells and mouse blood lymphocytes. HCC-94 cells were used, since the transfection efficiency of primary endometrial stromal cells is very low. The endogenous expression of MNSF $\beta$ detected in HCC-94 cells was either downregulated by RNA interference or upregulated by overexpression. These HCC-94 cell culture supernatants containing MNSF $\beta$ protein at different levels were subsequently added to in vitro cultures of mouse blood lymphocytes. The secretion of IL-4 from the lymphocytes was induced by overexpressed MNSF $\beta$, whereas TNF $\alpha$ secretion was inhibited. These effects reduced with time and could be immunoneutralized by antiMNSF $\beta$ antibody, partially verifying the hypothesis; that is, during the implantation process, increased intrauterine expression and secretion of MNSF $\beta$ at the interimplantation sites may contribute to the establishment of fetomaternal immunotolerance by regulating cytokine secretion from infiltrated lymphocytes. So the results of experiment indicate that MNSF $\beta$ differentially induced the secretion of IL-4 but inhibited the secretion of TNF $\alpha$ from mouse lymphocytes.

It was previously reported that MNSF $\beta$ protein is produced by $\mathrm{T}$ cells and that MNSF $\beta$ could suppress IL4 secretion from bone-marrow-derived mast cells (BMMC) and type-2 helper $\mathrm{T}$ cells [9]. In contrast in the present study, no detectable MNSF $\beta$ expression was observed in lymphocytes collected from mouse peripheral blood, while a stimulatory effect of MNSF $\beta$ on IL- 4 secretion from these lymphocytes was observed. This could be immunoneutralized by anti-MNSF $\beta$, supporting the observation. In the previous studies, the BMMC cells were sensitized with antiDNP IgE monoclonal antibody, and the type- 2 helper $\mathrm{T}$ cells were activated by concanavalin A whereas the mouse peripheral blood lymphocytes used in the present study were not artificially stimulated. This difference might explain effects of MNSF $\beta$ on IL-4 secretion. Furthermore, since MNSF $\beta$ could inhibit the proliferation of $\mathrm{T}$ cells and $\mathrm{B}$ cells $[6,7]$, it is possible that MNSF $\beta$ might inhibit the proliferation of TNF $\alpha$-secreting lymphocytes collected from mouse blood, leading to an abundance of IL-4-secreting lymphocytes, resulting in the increase of IL- 4 secretion. This conflict needs to be further investigated.

To explore the mechanisms underlying the roles of MNSF $\beta$ protein during embryo implantation, we previously determined the effects of our specific anti-MNSF $\beta$ antibody in the gene expression pattern at implantation sites. The results suggested that MNSF $\beta$ might play critical roles in early pregnancy not only through its contribution to the establishment of fetomaternal immune tolerance but also via actions on the development and invasion of the embryo [12]. Since coculture models of embryo with uterine endometrial cells has been successfully used to investigate the mechanisms of implantation in vitro $[15,20-22]$ and MNSF $\beta$ expression was demonstrated in both mouse embryonic cells and endometrial cells, we examined the in vitro effect of anti-MNSF $\beta$ antibody on mouse embryo implantation in such a coculture model. As expected, without treatment, mouse embryos from $\mathrm{d} 3.5$ pregnant mice adhered to the endometrial stromal cells and developed normally on the endometrial cell monolayer, while those endometrial stromal cells around the embryonic cells underwent decidualization-like morphological changes. Furthermore, abundant expression of MNSF $\beta$ protein was observed throughout the coculture process. Consistent with the previous in vivo data [12], immunoneutralization of the MNSF $\beta$ produced by cocultured embryonic and endometrial stromal cells significantly disturbed the normal development of mouse d3.5 embryo in vitro, further indicating that nonimmunological functions of MNSF $\beta$ protein contribute to the fetomaternal interaction.

Collectively, our results demonstrate that MNSF $\beta$ can stimulate IL- 4 secretion and inhibit TNF $\alpha$ secretion from mouse blood lymphocytes through a paracrine pathway in vitro, suggesting that MNSF $\beta$ protein might be involved in the establishment and maintenance of fetomaternal immune tolerance during the implantation process by regulating the functions of uterine lymphocytes. Furthermore, the expression of MNSF $\beta$ protein was detected both in mouse embryonic and endometrial cells cocultured in vitro, and anti-MNSF $\beta$ antibody could significantly inhibit the in vitro implantation of mouse embryo, suggesting that MNSF $\beta$ protein might also play critical roles in the development of the embryo during the implantation process.

\section{Acknowledgments}

This work was supported by a grant of the Innovation Programme of Chinese Academy (KSCX2-EW-R-06) and a grant of the National Natural Science Foundation of China (81070490). LAS is supported by an Australian NHMRC Fellowship (\#388901).

\section{References}

[1] C. Simón, C. Moreno, J. Remohí, and A. Pellicer, "Cytokines and embryo implantation," Journal of Reproductive Immunology, vol. 39, no. 1-2, pp. 117-131, 1998.

[2] M. N. Fukuda and S. Nozawa, "Trophinin, tastin, and bystin: a complex mediating unique attachment between trophoblastic and endometrial epithelial cells at their respective apical cell membranes," Seminars in Reproductive Endocrinology, vol. 17, no. 3, pp. 229-234, 1999.

[3] R. Bulla, F. Fischetti, F. Bossi, and F. Tedesco, "Feto-maternal immune interaction at the placental level," Lupus, vol. 13, no. 9, pp. 625-629, 2004.

[4] V. R. Aluvihare, M. Kallikourdis, and A. G. Betz, "Tolerance, suppression and the fetal allograft," Journal of Molecular Medicine, vol. 83, no. 2, pp. 88-96, 2005.

[5] S. Daher, K. D. A. G. Denardi, M. H. S. L. Blotta et al., "Cytokines in recurrent pregnancy loss," Journal of Reproductive Immunology, vol. 62, no. 1-2, pp. 151-157, 2004.

[6] M. Nakamura, H. Ogawa, and T. Tsunematsu, "Isolation and characterization of a monoclonal nonspecific suppressor 
factor (MNSF) produced by a T cell hybridoma," Journal of Immunology, vol. 136, no. 8, pp. 2904-2909, 1986.

[7] M. Nakamura, H. Ogawa, and T. Tsunematsu, "Characterization of monoclonal nonspecific suppressor factor (MNSF) with the use of a monoclonal antibody," Journal of Immunology, vol. 138, no. 6, pp. 1799-1803, 1987.

[8] M. Nakamura, R. M. Xavier, and Y. Tanigawa, "Monoclonal non-specific suppressor factor (MNSF) inhibits the IL4 secretion by bone marrow-derived mast cell (BMMC)," FEBS Letters, vol. 339, no. 3, pp. 239-242, 1994.

[9] M. Nakamura, R. M. Xavier, and Y. Tanigawa, "Monoclonal nonspecific suppressor factor $\beta$ inhibits interleukin-4 secretion by a type- 2 helper T cell clone," European Journal of Immunology, vol. 25, no. 8, pp. 2417-2419, 1995.

[10] M. Nakamura, R. M. Xavier, T. Tsunematsu, and Y. Tanigawa, "Molecular cloning and characterization of a cDNA encoding monoclonal nonspecific suppressor factor," Proceedings of the National Academy of Sciences of the United States of America, vol. 92, no. 8, pp. 3463-3467, 1995.

[11] G. Y. Nie, Y. Li, A. L. Hampton, L. A. Salamonsen, J. A. Clements, and J. K. Findlay, "Identification of monoclonal nonspecific suppressor factor beta $(\mathrm{MNSF} \beta)$ as one of the genes differentially expressed at implantation sites compared to interimplantation sites in the mouse uterus," Molecular Reproduction and Development, vol. 55, no. 4, pp. 351-363, 2000.

[12] J. Wang, P. H. Zhe, Y. N. Gui, L. A. Salamonsen, and X. S. Qing, "Immunoneutralization of endometrial monoclonal nonspecific suppressor factor beta (MNSF $\beta$ ) inhibits mouse embryo implantation in vivo," Molecular Reproduction and Development, vol. 74, no. 11, pp. 1419-1427, 2007.

[13] G. Gaunt and K. Ramin, "Immunological tolerance of the human fetus," American Journal of Perinatology, vol. 18, no. 6, pp. 299-312, 2001.

[14] M. Nakamura and S. Omura, "Quercetin regulates the inhibitory effect of monoclonal non-specific suppressor factor $\beta$ on tumor necrosis factor- $\alpha$ production in LPS-stimulated macrophages," Bioscience, Biotechnology and Biochemistry, vol. 72, no. 7, pp. 1915-1920, 2008.

[15] J. Carver, K. Martin, I. Spyropoulou, D. Barlow, I. Sargent, and H. Mardon, "An in-vitro model for stromal invasion during implantation of the human blastocyst," Human Reproduction, vol. 18, no. 2, pp. 283-290, 2003.

[16] Y. Tan, D. Tan, M. He et al., "A model for implantation: coculture of blastocysts and uterine endometrium in mice," Biology of Reproduction, vol. 72, no. 3, pp. 556-561, 2005.

[17] S. A. McCormack and S. R. Glasser, "Differential response of individual uterine cell types from immature rats treated with estradiol," Endocrinology, vol. 106, no. 5, pp. 1634-1649, 1980.

[18] R. L. Jones, N. J. Hannan, T. J. Kaitu'u, J. Zhang, and L. A. Salamonsen, "Identification of chemokines important for leukocyte recruitment to the human endometrium at the times of embryo implantation and menstruation," Journal of Clinical Endocrinology and Metabolism, vol. 89, no. 12, pp. 6155-6167, 2004.

[19] S. Saito, "Cytokine network at the feto-maternal interface," Journal of Reproductive Immunology, vol. 47, no. 2, pp. 87-103, 2000.

[20] J. Sengupta and D. Ghosh, "Experimental models for human implantation," Indian Journal of Physiology and Pharmacology, vol. 47, no. 1, pp. 10-26, 2003.

[21] R. M. Popovici, N. K. Betzler, M. S. Krause et al., "Gene expression profiling of human endometrial-trophoblast interaction in a coculture model," Endocrinology, vol. 147, no. 12, pp. 5662-5675, 2006.

[22] B. Gellersen, K. Reimann, A. Samalecos, S. Aupers, and A. M. Bamberger, "Invasiveness of human endometrial stromal cells is promoted by decidualization and by trophoblast-derived signals," Human Reproduction, vol. 25, no. 4, pp. 862-873, 2010. 


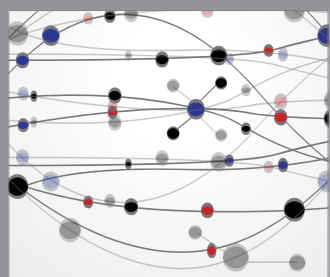

The Scientific World Journal
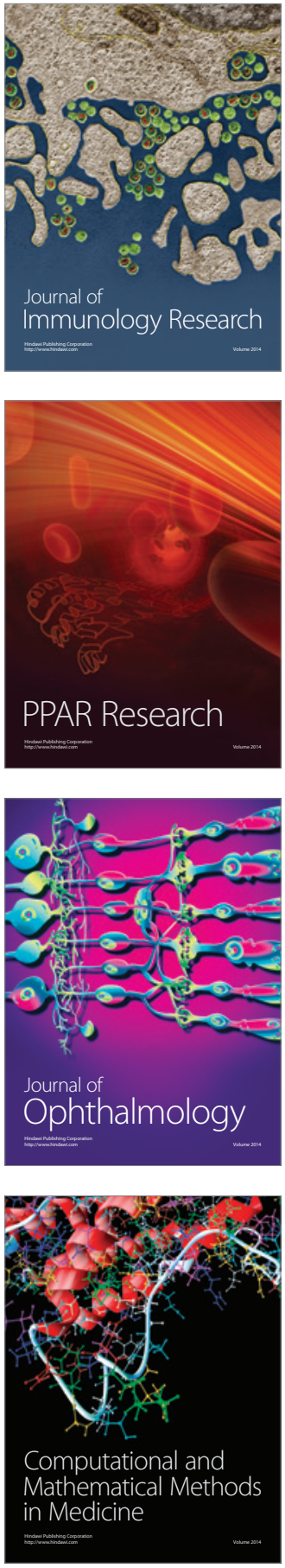

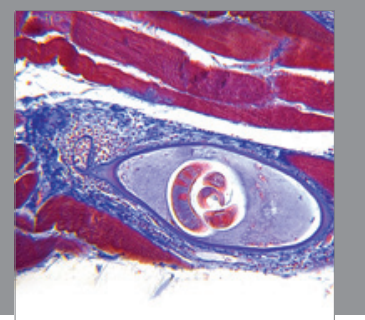

Gastroenterology

Research and Practice
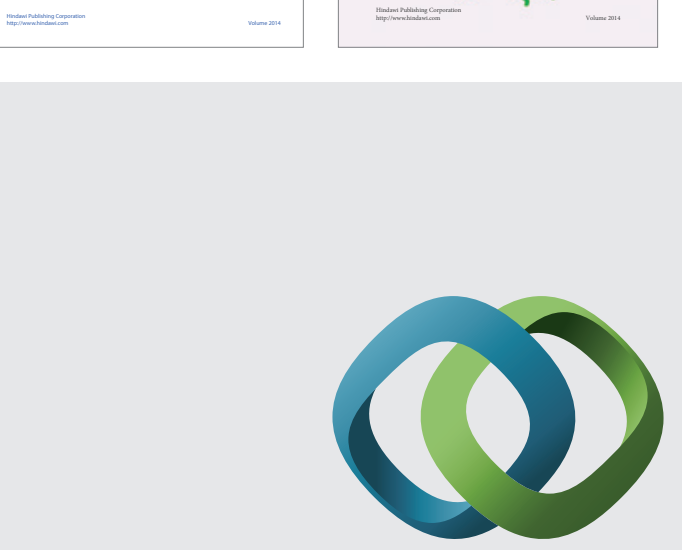

\section{Hindawi}

Submit your manuscripts at

http://www.hindawi.com
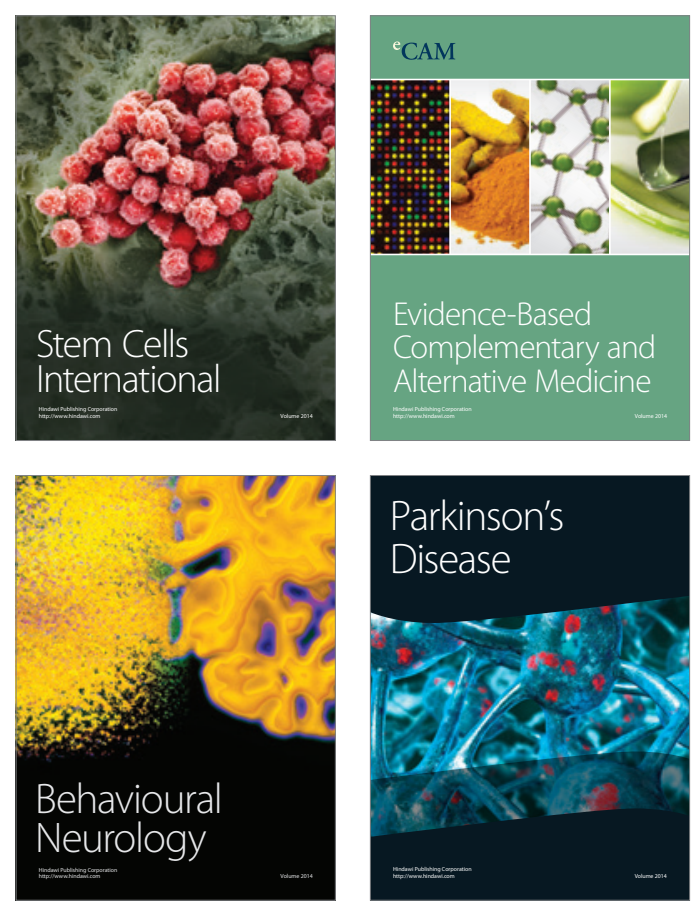

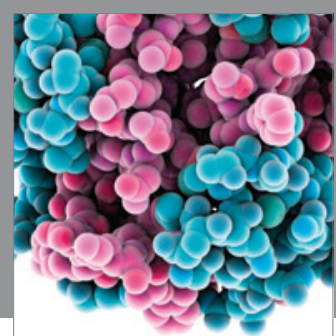

Journal of
Diabetes Research

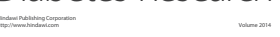

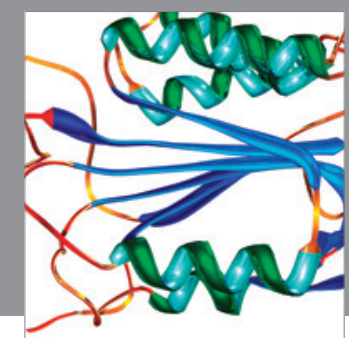

Disease Markers
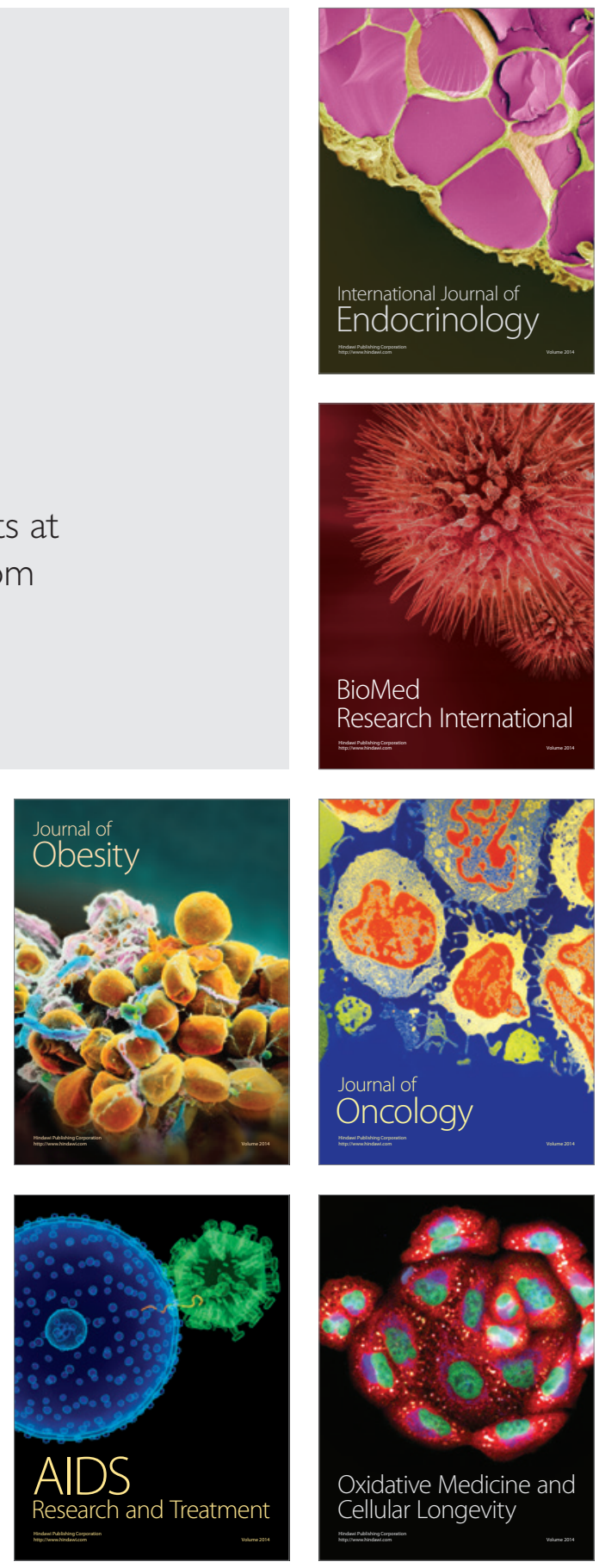